\title{
Breast Density and Risk of Interval Cancers: The Effect of Annual Versus Biennial Screening Mammography Policies in Canada
}

\author{
Jean Morag Seely, $M D^{1,2,3}$, Susan Elizabeth Peddle, $M D^{3}$, \\ Huiming Yang, MD ${ }^{4}$, Anna M. Chiarelli ${ }^{5}$, Megan McCallum ${ }^{6}$, \\ Gopinath Narasimhan ${ }^{7}$, Dianne Zakaria ${ }^{8} \oplus$, Craig C. Earle, ${ }^{9,10}$, \\ Sharon Fung ${ }^{10}$, Heather Bryant, MD, PhD, CCFP ${ }^{10}$, Erika Nicholson' ', \\ Chris Politis ${ }^{10}$, and Wendie Berg, MD, PhD ${ }^{12,13}$
}

\begin{abstract}
Regular screening mammography reduces breast cancer mortality. However, in women with dense breasts, the performance of screening mammography is reduced, which is reflected in higher interval cancer rates (ICR). In Canada, population-based screening mammography programs generally screen women biennially; however, some provinces and territories offer annual mammography for women with dense breast tissue routinely and/or on recommendation of the radiologist. This study compared the ICRs in those breast screening programs with a policy of annual vs. those with biennial screening for women with dense breasts. Among 148,575 women with dense breasts screened between 2008 to 2010, there were 288 invasive interval breast cancers; screening programs with policies offering annual screening for women with dense breasts had fewer interval cancers 63/70,8I4 (ICR 0.89/1000, 95\% Cl: 0.67-I.II) compared with those with policies of usual biennial screening 225/77,76I (ICR $1.45 / 1000$ (annualized), 95\% Cl: I.19-I.72) i.e. 63\% higher $(\mathrm{p}=0.0016)$. In screening programs where radiologists' screening recommendations were able to be analyzed, a total of 76,103 women were screened, with 87 interval cancers; the ICR was lower for recommended annual $(65 / 69,650$, ICR $0.93 / 1000,95 \% \mathrm{Cl}$ : $0.7 \mathrm{I}, \mathrm{I}$. I6) versus recommended biennial screening $(22 / 6,453$, ICR I.70/I000 (annualized), $95 \% \mathrm{Cl}: 0.70,2.7 \mathrm{I})(\mathrm{p}=0.0605)$. Screening program policies of annual as compared with biennial screening in women with dense breasts had the greatest impact on reducing interval cancer rates. We review our results in the context of current dense breast notification in Canada.
\end{abstract}

\section{Résumé}

La mammographie régulière de dépistage abaisse la mortalité par cancer du sein. Cependant, chez les femmes dont les seins sont denses, les performances de la mammographie de dépistage sont réduites, ce qui se manifeste par des taux de cancers dans l'intervalle (ICR) plus élevés. Au Canada, les programmes de mammographies de dépistage basés sur la population contactent habituellement les femmes tous les deux ans. Certaines provinces et des territoires proposent de façon régulière une mammographie annuelle aux femmes ayant un tissu mammaire dense et/ou sur recommandation du radiologiste. Cette étude a comparé les ICR chez les femmes ayant un tissu mammaire dense et participant à ces programmes de dépistage sur une base

\footnotetext{
I Ottawa Hospital Research Institute, Ottawa, Ontario, Canada

${ }^{2}$ Department of Radiology and Surgery, University of Ottawa, Ottawa, Ontario, Canada

${ }^{3}$ Department of Medical Imaging, The Ottawa Hospital, Ottawa, Ontario, Canada

${ }^{4}$ Alberta Health Services, Edmonton, Alberta, Canada

${ }^{5}$ Ontario Health, Toronto, Ontario, Canada

${ }^{6}$ Government of the Northwest Territories, Yellowknife, Northwest Territories, Canada

${ }^{7}$ Saskatchewan Cancer Agency, Regina, Saskatchewan, Canada

${ }^{8}$ Public Health Agency of Canada, Ottawa, Ontario, Canada

${ }^{9}$ Department of Medicine, University of Toronto, Toronto, Ontario, Canada

${ }^{10}$ Canadian Partnership Against Cancer, Toronto, Ontario, Canada

1 Canadian Partnership Against Cancer, Halifax, Nova Scotia, Canada

${ }^{12}$ Department of Radiology, University of Pittsburgh School of Medicine, Pittsburgh, PA, USA

${ }^{13}$ UPMC Magee-Womens Hospital, Pittsburgh, PA, USA
} 
annuelle ou tous les deux ans. Parmi les I48 575 femmes ayant des seins denses examinées entre 2008 et 2010 , il y a eu 288 cancers du sein invasifs dans l'intervalle. Les programmes de dépistage appliquant une politique d'examen annuel pour les femmes ayant des seins denses ont eu moins de cancers de l'intervalle $(63 / 70814$, soit 0,89 ICR/I000, IC à $95 \%: 0,67$ à I,II) que les programmes appliquant une politique d'examen tous les deux ans (225/77 76I, I,45 ICR/I000 [annualisés], IC à $95 \%$ : I, I 9 à I,72), c.-à-d. $63 \%$ de plus $(P>0,0016)$. Dans les programmes de dépistage où les recommandations des radiologistes ont pu être analysées, un total de 76103 femmes a été examiné avec 87 cancers dans l'intervalle; l'ICR a été plus faible lorsque l'examen annuel était recommandé $(65 / 69650,0,93 \mathrm{ICR} / \mathrm{I000}$, IC à $95 \%: 0,7 \mathrm{I}$ à I, I6) par rapport à la politique recommandée de dépistage tous les deux ans (22/6 453, I,70 ICR/I 000 [annualisés], IC à $95 \%: 0,70$ à 2,7I) $(P>0,0605)$. Les politiques de programmes de dépistage annuel comparées aux politiques de dépistage tous les deux ans chez les femmes ayant un tissu mammaire dense ont eu le plus grand effet sur la réduction des taux de cancer dans l'intervalle. Nous revoyons nos résultats dans le contexte de la notification actuelle de seins denses au Canada.

\section{Keywords}

breast density, screening mammography, interval cancer, supplemental screening, MRI

\section{Introduction}

Breast cancer mortality is reduced by the detection of small, node-negative cancers. ${ }^{1,2}$ But, for women with dense breasts, the sensitivity of mammography is limited due to the masking effect of dense tissue. ${ }^{3}$ In addition, dense breast tissue is one of the strongest and most common independent risk factors for breast cancer. ${ }^{4-6}$ As such, it is critical to understand the significance of breast density as it directly affects performance of screening mammography and impacts patient outcomes. In Canada, a review of breast tissue density is important within the context of well-established population-based screening programs with overall high performance indicators. Both a reduced cancer detection rate $(\mathrm{CDR})$ and lower reduction in breast cancer mortality have been demonstrated in screening mammography for women with dense breasts. ${ }^{7-9}$ Women with non-dense breasts screened regularly have a $41 \%$ mortality reduction from screening mammography, while women with dense breasts have a $13 \%$ mortality reduction. ${ }^{10}$ A higher rate of advanced breast cancers has been shown in women with dense breasts ${ }^{11}$ (see Figure 1). Women with extremely dense breasts have a 4- to 5-fold greater risk of developing breast cancer compared to women with fatty breasts. ${ }^{3,6}$ Compared to women with scattered fibroglandular density (non-dense), women with heterogeneously dense and extremely dense breasts are 1.4-1.6 and 1.5-2.1 times more likely to develop breast cancer respectively. ${ }^{12}$ Breast tissue density is considered a biomarker, defined as what is used to "detect or confirm presence of a disease or condition of interest or to identify individuals with a subtype of the disease."13-16 Breast density can predict the effectiveness of various treatment interventions for breast cancer such as response to chemotherapy ${ }^{17}$ and surgery, with higher rates of locoregional recurrence in women with dense breasts. ${ }^{17-20}$

Breast density refers to the amount of fibroglandular tissue relative to fat and is determined either visually or quantitatively on mammography. The BI-RADS ${ }^{\circledR} 5$ th edition includes 4 categories of breast density, reflecting the densest portion of the breast: A (fatty), B (scattered fibroglandular density), C (heterogeneously dense) and D (extremely dense). ${ }^{21}$ The 2013 BI-RADS 5th ed. density classification is based on the masking effect of breast tissue density, while the 2003 BIRADS 4th ed. ${ }^{22}$ was based on visually estimated percentage breast density; both are associated with high rates of inter- and intra-observer variability. ${ }^{23,24}$ There is less variability for women with extremely dense than with heterogeneously dense breast tissue. ${ }^{24,25}$ Dense breasts are normal and common: $43.3 \%$ of women 40 to 74 years of age have heterogeneously or extremely dense breasts, and the incidence decreases with age, particularly around menopause. ${ }^{25}$ Only $7.4 \%$ of women have extremely dense breasts. ${ }^{25}$ Knowledge of implications of breast density on the part of radiologists and referring physicians is essential. In addition, women want to be informed of their breast density. ${ }^{26}$ Patient advocacy groups in Canada and across the world are lobbying to ensure density notification for all women. ${ }^{27,28}$ At the time of writing in Canada, Alberta, Manitoba, Nova Scotia, New Brunswick, British Columbia and Prince Edward Island formally notify screening participants of breast tissue density using BIRADS 5th ed. categories in their results letters, while Ontario, Newfoundland and Saskatchewan notify screened women if they are in the densest category (i.e. extremely dense, category $\mathrm{D}$, previously defined as visually $\geq 75 \%$ dense). In addition to provincial variability regarding density notification, recommended age to begin screening is under the jurisdiction of each province/territory (Table 1)

The sensitivity of mammography decreases with increasing breast density with a range of $81-93 \%$ for fatty breasts, $84-90 \%$ for breasts with scattered fibroglandular density, $69-81 \%$ for heterogeneously dense breasts and $57-71 \%$ for extremely dense breasts in women $40-74$ years of age ${ }^{30}$ (see Figure 2). About $45 \%$ of invasive cancers have associated microcalcifications, ${ }^{31}$ and calcifications remain visible even in the densest breasts. The remaining $55 \%$ of noncalcified cancers manifest as masses or asymmetries which are only visible mammographically if there is some surrounding fat and/or associated architectural distortion. 


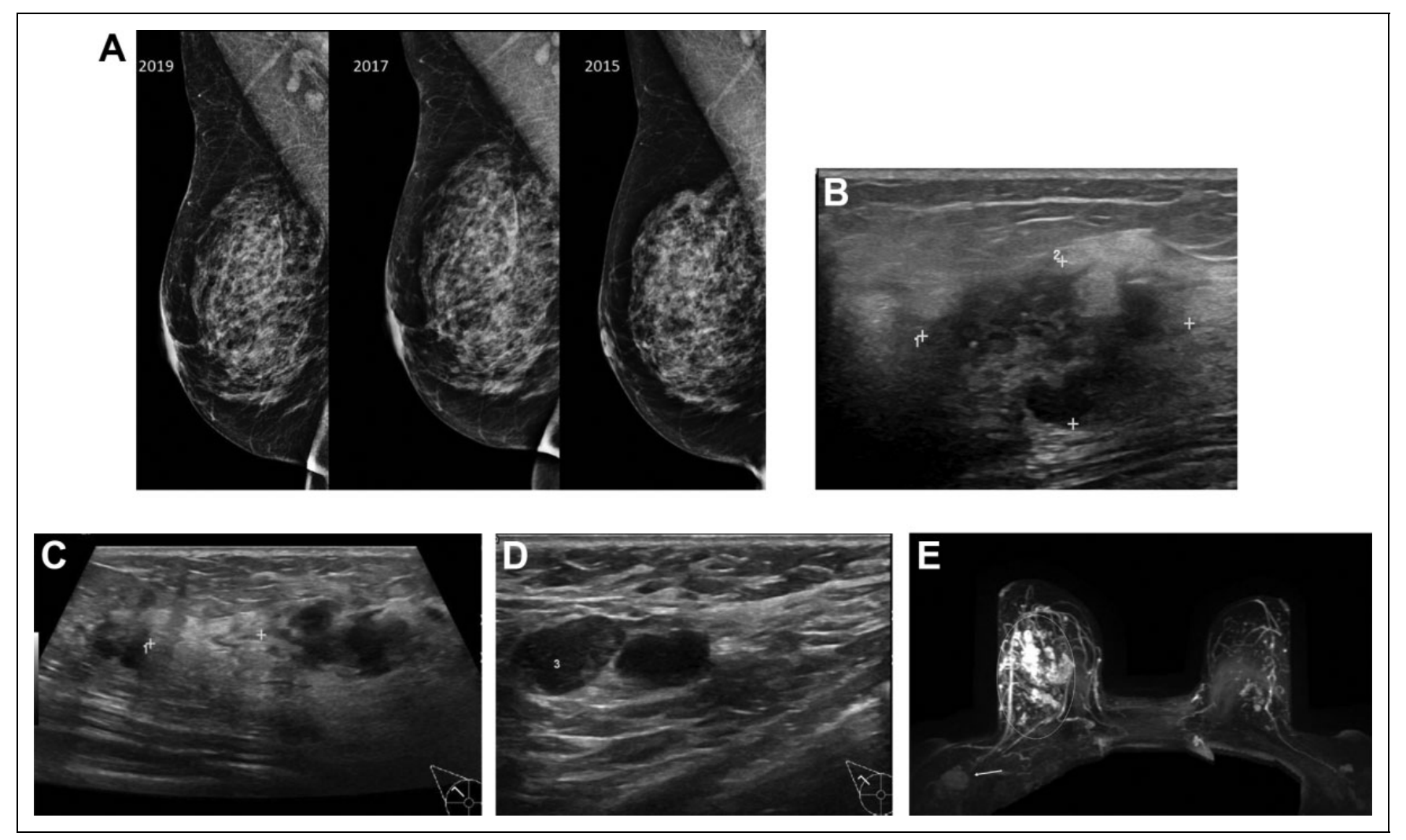

Figure I. 60-year-old woman with no family history of breast cancer undergoing regular screening mammography every 2 years, with heterogeneously dense breasts (BI-RADS Category C). Two months after her last normal screening mammogram, she presented with a new right palpable breast mass at 12 o'clock in her right breast. A, Demonstrates mediolateral oblique (MLO) views from her screening mammograms from 2019, 2017 and 2015, all normal. Breast tissue density masked the tumors found 2 months later with ultrasound. B, A right breast ultrasound performed for evaluation of the palpable mass shows a $3 \times 1.8 \mathrm{~cm}$ irregular heterogeneous mass at the site of the palpable mass. C, additional $2.5 \mathrm{~cm}$ mass was found at $\mathrm{II}: 00,1.8 \mathrm{~cm}$ away from the clinical finding. D, Axillary ultrasound shows the 2 enlarged axillary lymph nodes, both of which were proven malignant. E, Axial maximum intensity projection (MIP) image of the breast on contrast-enhanced breast MRI shows the multicentric enhancing tumors involving most of the right breast (circle) with right axillary lymphadenopathy (arrow), in keeping with locally advanced right breast cancer. Final pathology was invasive ductal carcinoma, ER and PR negative, HER2 neu positive, T3N2M0. The patient was treated with neoadjuvant chemotherapy and subsequent right mastectomy and targeted localized sentinel lymph node dissection.

Because dense tissue masks some cancers on mammographic screening, breast cancers are more likely to present with symptoms in the interval between recommended screens in women with dense breasts. Interval cancers are cancers found during the interval after a normal screening mammogram and before the next screen is due. ${ }^{29}$ Some interval cancers are newly developed biologically aggressive tumors (e.g. triple negative or HER2 neu positive cancers), while others are those missed on screening mammography. Women with dense breasts experience more interval cancers, likely related to the masking effect of density. ${ }^{32,33}$ Interval cancers are 13-31 times more likely in extremely dense breasts as compared with fatty breasts. ${ }^{3,34,35}$ Such interval cancers are often more aggressive and in several studies are more likely to be larger and to have spread to axillary nodes at presentation than are cancers detected on screening. ${ }^{33,36-40}$ Interval cancers are associated with a 2-3 times greater mortality rate in women with dense breasts. ${ }^{7,41}$

One measure of the effectiveness of a screening program is the interval cancer rate (ICR), typically for invasive cancers, also referred to as post-invasive cancer rate. ${ }^{29,42}$ The ICR reflects the sensitivity of a screening program and depends on cancer incidence within a population. An ICR exceeding 1 per 1000 screened women per year within a population with a cancer incidence of $4 / 1000$ or sensitivity $<75 \%$ suggests an ineffective screening strategy. ${ }^{30}$ In Canada, screening programs demonstrate overall high sensitivity of $84.3 \%{ }^{43}$ and an incidence of 3.7 invasive cancers per 1000 women screened; the targets for ICR are $<0.6$ per 1000 for annual screening and $<1.2$ per 1000 for 12 to 24 months after screening. ${ }^{29}$ Houssami et $\mathrm{a}^{37}$ evaluated screening programs worldwide and showed that biennial and triennial screening increase ICR, with many interval cancers found in the second or third years, and an average ICR of $<0.8$ per 1000 with annual screening.

Although annual screening mammography is performed in the USA and parts of Canada, and every 18 months for women age 40-54 in some counties in Sweden, most population-based screening mammography is performed biennially. ${ }^{27,29}$ While a few studies have predicted a reduction in interval cancers of $36 \%$ to $50 \%$ when going from triennial to annual screening,, 84 to date, there are little trial or observational data on the 
Table I. Organized Screening Programs in Canada and Density Notification.

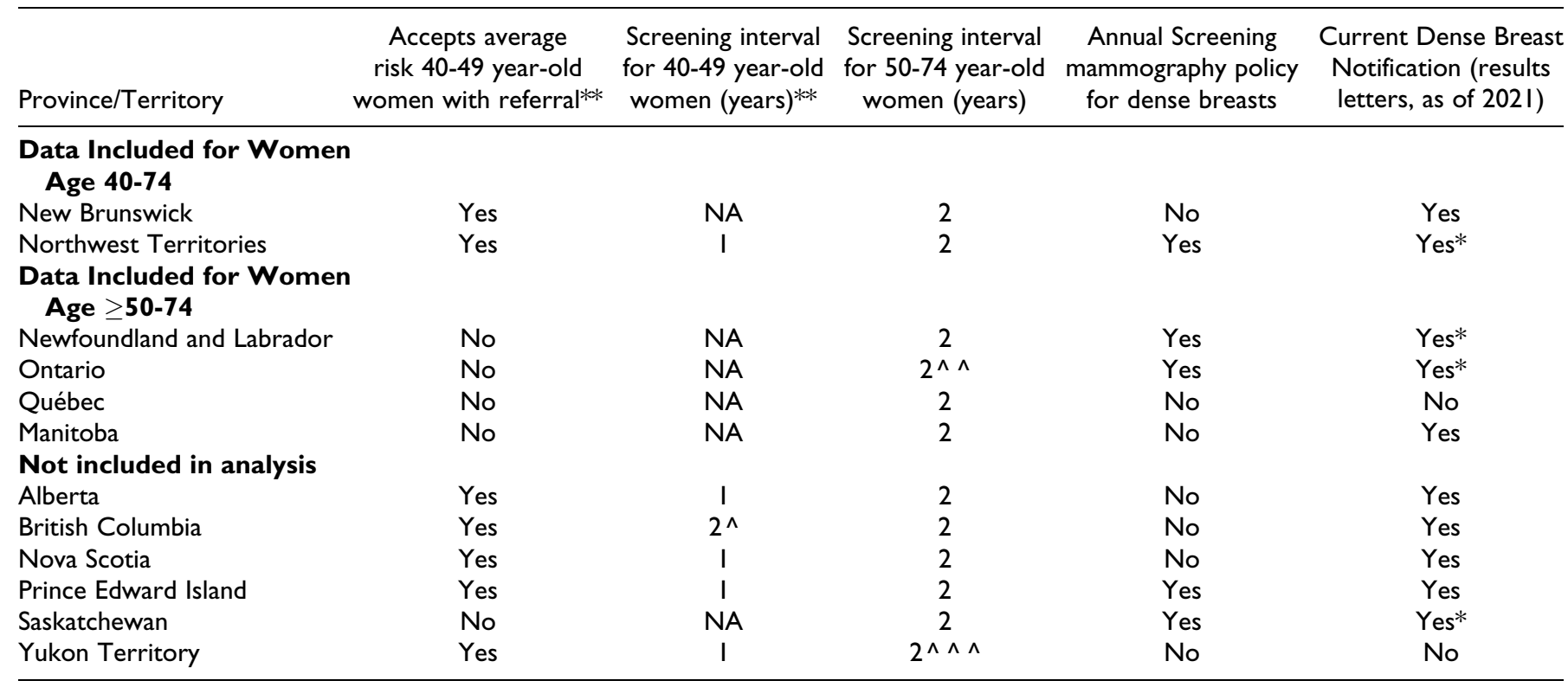

Note that Nunavut has no organized screening program.

*Notification only for $\geq 75 \%$ dense (BI-RADS D, extremely dense); density notification commenced in British Columbia in 2018.

$\mathrm{NA}=$ not applicable.

$\wedge$ accepted within 18 months, and for a woman with a first degree relative with breast cancer, is accepted within 12 months.

$\wedge \wedge$ accepted after II months with self-referral.

$\wedge \wedge \wedge$ accepted after 12 months with self-referral. ** 29

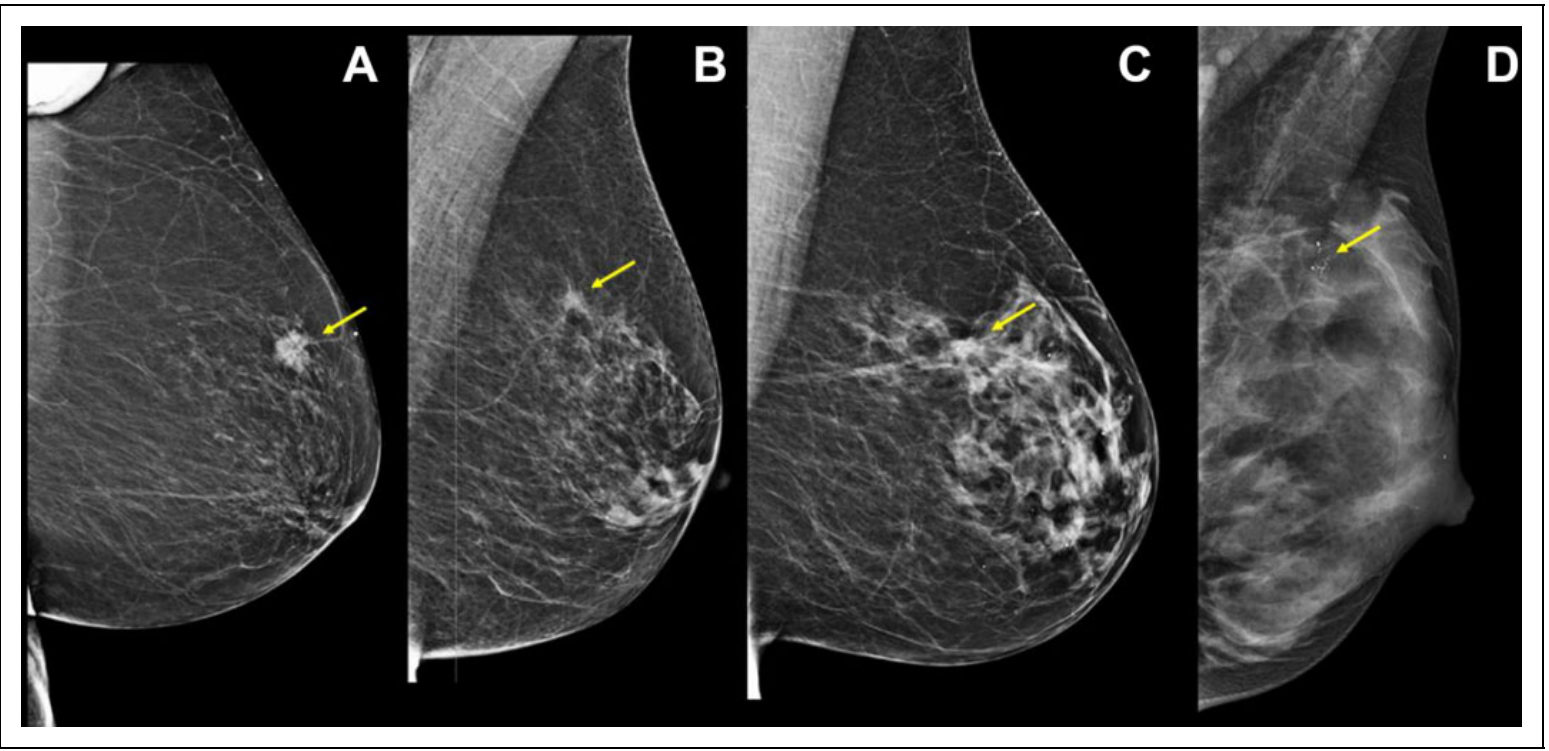

Figure 2. Malignancies in 4 women with each of 4 categories of breast tissue density, BI-RADS categories A (fatty replaced), B (scattered fibroglandular density), $C$ (heterogeneously dense), and D (extremely dense), in 4 different patients. Each patient has a cancer in their upper breast (arrows). As density increases, the detection of the cancer becomes more challenging and only the presence of calcifications allows detection of a $1.5 \mathrm{~cm}$ cancer, the extent otherwise masked by the dense breast tissue in a patient with category D, with axillary nodal metastases also present.

potential stage shift and mortality reduction associated with higher frequency screening in women with dense breasts. ${ }^{45}$

The purpose of our study was to evaluate the impact of population-based annual screening versus biennial screening policy on the ICR for women with dense breasts.

\section{Materials and Methods}

\section{Patient Population}

We used information available from the Canadian Breast Cancer Screening Database (CBCSD), which is operated and 
maintained by the Public Health Agency of Canada (PHAC) on behalf of the Canadian Breast Cancer Screening Network. ${ }^{29,46}$ New Brunswick (NB) data for this analysis was contributed by the NB Cancer Network (NBCN). Data were included from provincial screening programs that provided information on breast density (BI-RADS 4th ed.), interval cancers, family history, and jurisdictional policy on supplemental screening for all women (aged $\geq 40$ ) with extremely dense breasts (defined as visually $\geq 75 \%$ glandular, unless the classification method necessitated use of $\geq 50 \%$, as defined in NB), only results from women with no first-degree family history, known recommended screening interval and not referred for follow-up testing were included. Records with missing data were excluded. Screening programs from Quebec (QC), Ontario (ON) and Newfoundland (NL) included in the analysis did not submit screening information for women younger than 50 years old. ${ }^{29}$ Six jurisdictions : Manitoba (MB), QC, ON, NL, Northwest Territories (NT) and New Brunswick (NB) contributed data with the necessary information; 4 jurisdictions (MB, ON, NL and NT) also included the radiologists' screening interval recommendation (as radiologists may recommend an earlier return visit than the general policy if they deem it indicated). ${ }^{29,46}$ Radiologists' recommendations for annual screening are based on their assessment that included clinical impression, breast density, and personal/family risk factors.

Screen years 2008-2010 were selected as the most recent screens available with interval cancer information. During 2008-2010 inclusively, all the breast screening programs used two-view, mostly analog mammography, provided at designated centers with a single radiologist interpretation. During this period in Canada, the proportion of mammograms performed on film decreased from $71.5 \%$ in 2008 to $41.0 \%$ in 2010 , and in the 6 jurisdictions studied, $57 \%$ of mammograms were film, $22 \%$ digital radiography (DR) and $21 \%$ digital computed radiology (CR) ${ }^{29}$ Entry to all programs was based upon self-referral except in the jurisdictions that required referral for women age 40-49, with jurisdiction-wide geographic access provided using a mixture of clinics and mobile services. Depending on time period and jurisdiction, women might have received personalized invitation letters to participate in screening prior to enrollment. After enrollment, women received periodic reminder letters for screening at 1 or 2 years, based on the screening interval policy or radiologist recommendation. In all jurisdictions, breast cancer care for women, including those participating in screening, was managed through family physicians who received results of diagnostic tests and who then managed referral to tertiary services or managed via direct referral from the screening centers.

\section{Analysis}

The main outcome examined was the frequency of invasive interval cancers among women with the densest breasts. Interval cancers were defined as cancers occurring between regular screening visits, after a negative or benign mammographic assessment, i.e. within 1-2 years of the last screen. ICRs for biennial (24 month) screening interval are presented as averaged annual rates (annualized) to facilitate comparison with the annual (12 month) screening. Comparison was performed using the chi-square test based on per 1000/year results. Screening programs were combined according to the interval policy or radiologist recommendation to facilitate analysis.

\section{Results}

A total of 148,575 women were included in the analysis that compared the impact of jurisdictional policies in women with the densest breasts. This represents approximately $17.5 \%$ $(148,575 / 864,386)$ of all women screened in these jurisdictions in 1 year (2009). ${ }^{47}$ Of these, 288 women were diagnosed with interval cancers (Table 2). Of the 6 screening programs included, 3 offered routine annual mammography screening for women with dense breasts, and 3 did not. In the jurisdictions routinely providing annual screening, the rate of interval cancers was 0.89/1000 women screened/year (95\% CI: 0.67-1.11) and for those providing biennial screening, the annualized ICR was $1.45 / 1000$ women (95\% CI: 1.19-1.72) screened/year, or $63 \%$ greater $(p=0.0016)$. When screening interval policy and radiologists recommendations were combined, there were 76,103 screened women eligible for the analysis, 87 of whom had invasive interval cancers: 65 of the 69,650 screened with annual recommendations had ICR 0.93/1000 (95\% CI: $0.71-1.16)$ and 22 of 6453 screened with biennial recommendations had a higher annualized ICR 1.70/1000 (95\% CI:0.702.71 $)(p=0.0605)$.

\section{Discussion}

In our study, women with dense breasts who received a screening recommendation by jurisdictional policy for biennial screening had an annualized ICR of 1.45 per 1000 as compared to 0.89 per 1000 for annual screening policy, 1.63 times higher $(\mathrm{p}=.0016)$. Those who had a radiologist's recommendation of biennial screening had an annualized rate of interval cancers that was almost twice that of women receiving an annual screening recommendation (1.7 vs 0.93 per 1000 women screened/ year, $\mathrm{p}=0.0605$ ) trending to significance. By comparison, in Canada, 2009-2010, for all screened women age 50-69 years, including all categories of breast tissue densities, the ICR (postscreen invasive cancer rate) was $0.74 / 1000$ within 12 months and $1.27 / 1000$ between 12 and 24 months of a normal screen. ${ }^{29}$ Although it would have been optimal to compare the ICR of women with dense to non-dense breasts, these data were not available within the jurisdictions studied. To our knowledge, this is the first study that has shown the impact of annual vs biennial screening policies on ICRs in women with dense breast tissue. These results suggest the need to prospectively assess the impact of annual screening in dense breasts.

ICR has become an important method of assessing the effectiveness of a screening program. Interval cancers represent a shortcoming in mammographic screening because of unfavorable tumor characteristics compared with screen-detected 
Table 2. Impact of Screening Interval on Invasive Interval Cancers for Women with Dense Breasts Screened Between 2008 and 2010.

\begin{tabular}{|c|c|c|c|c|c|}
\hline & $\begin{array}{l}\text { Total number of } \\
\text { women screened } \\
(2008-2010)\end{array}$ & $\begin{array}{c}\text { Total number of } \\
\text { women with interval } \\
\text { cancers }\end{array}$ & $\begin{array}{l}\text { Invasive interval cancer } \\
\text { rate/ } 1000 \text { women } \\
\text { screened }\end{array}$ & $\begin{array}{l}\text { Interval invasive cancer } \\
\text { rate per } 1000 \text { women } \\
\text { screened/yr** } \\
\text { (Annualized) }(95 \% \mathrm{Cl})\end{array}$ & P value* \\
\hline \multicolumn{6}{|c|}{$\begin{array}{l}\text { Recommendations by screening program } \\
\text { policy ( } 6 \text { jurisdictions) }\end{array}$} \\
\hline Annual screening & $70,8 \mid 4$ & 63 & 0.89 & $0.89(0.67, \mathrm{I} . \mathrm{II})$ & \\
\hline \multicolumn{6}{|c|}{$\begin{array}{l}\text { Recommendations by radiologist } \\
\text { and screening program } \\
\text { policy ( } 4 \text { jurisdictions) }\end{array}$} \\
\hline Annual screening & 69,650 & 65 & 0.93 & $0.93(0.71,1.16)$ & \\
\hline Biennial screening & 6,453 & 22 & 3.41 & $\mathrm{I} .70(0.70,2.7 \mathrm{I})$ & \\
\hline Total & 76,103 & 87 & & & 0.0605 \\
\hline
\end{tabular}

cancers. $^{48-53}$ Specifically, interval cancers are more likely to be larger and node positive at the time of diagnosis, with more advanced stage; these factors result in poorer outcomes. ${ }^{33,36,37}$ More advanced tumors require more aggressive therapy with respect to both surgery and either neoadjuvant or adjuvant therapy. ${ }^{54}$ A wide range of 17 to $30 \%$ of breast cancers detected in women in European population-based screening programs are interval cancers, the highest occurring in programs that screen triennially. ${ }^{37,55}$ A doubling of the ICR with biennial vs annual screening is well recognized, with a larger proportion occurring in the second year ${ }^{37}$; a recent study found that two thirds of the interval cancers occurred in the second year. $^{55}$ The majority of population-based screening programs are biennial and report a range of ICRs of 0.84 to 2.11 per $1000 .^{37,56}$ In Canada, between 2003 and 2010, the interval cancer rate among women with incident (subsequent) screens was between 1.25 and 1.28 per 1000 women within 12-24 months of their screen. The national target of $<1.2$ per 1000 screened women was only met in the years 2004, 2005 and 2007. ${ }^{29}$ During this period, the rate of invasive cancer detection was relatively stable at approximately 3.7 per 1000 women-screens.

In our study, the annualized ICR for biennial screening was significantly higher than the suggested target of less than 1 per 1000 for an effective screening program. Depending on the screening interval policy for jurisdictional policy or radiologist recommendation, the annualized ICR ranged from 1.45-1.7 per 1000 for biennial screening and was lower at 0.89-0.93 per 1000 with annual screening, within the suggested target. This suggests that annual screening mammography is a more effective screening strategy for women with dense breasts to meet suggested benchmarks for ICRs.

Despite the significantly lower ICR with annual screening for women with dense breasts, ICR still exceeded the Canadian benchmark of $<0.6$ per 1000 women within 12 months of screening. The negative impact of breast density on mammographic screening, mainly due to masking, highlights the need for more effective screening in women with dense breasts to ensure equal benefit from early cancer detection.

Dense breast tissue by both visual assessment and quantitative breast density software (such as Volpara ${ }^{\circledR}$ and Cumulus ${ }^{\circledR}$ ) correlates with reduced mammographic sensitivity and increased ICR. ${ }^{26,27,28,30}$ While there is growing recognition of the importance of modifying breast cancer risk factors within the control of women, including avoiding alcohol, regularly exercising, modifying diet and maintaining a healthy body weight, there remain non-modifiable risk factors including genetics, family history, early menarche/late menopause, nulliparity, chest wall radiation, previous atypia, and dense breast tissue. Risk assessment tools such as the Tyrer-Cuzick Breast Cancer Risk Model, version 8, which includes breast density $^{26,27}$ and emerging mammography-based deep learning models facilitate more accurate lifetime risk prediction of breast cancer. $^{32}$ Dense breast tissue remains an obstacle to early cancer detection.

Supplemental screening options have been evaluated and show further reductions in ICR in women with dense breasts. Observed results using various supplemental screening modalities are summarized in Table 3 . Incremental cancer detection in dense breasts has been demonstrated with multiple studies of supplemental screening with tomosynthesis, ${ }^{57-60}$ breast ultrasound, ${ }^{61}$ breast MRI, ${ }^{62-65}$ and more recently, with contrastenhanced mammography ${ }^{66,67}$ and molecular breast Imaging $(\mathrm{MBI})^{68-70}$ (Figure 3). The highest sustained incremental cancer detection rates (ICDR) are observed with breast MRI, with average ICDR of 14-20 per 1000 women in prevalence studies ${ }^{62,64,65}$ with sustained yield with incident rounds averaging ICDR of 5.8-8.6 per 1000 women screened. ${ }^{64,71}$ ICRs have been shown to be reduced with supplemental screening with ultrasound, ${ }^{62,72,73}$ breast MRI $^{64,65}$ and most recently, with tomosynthesis $^{74}$ (Figure 4 ). In the J-START randomized controlled study of supplemental screening ultrasound in women 
Table 3. Incremental Cancer Detection with Various Supplemental Screening Modalities and Impact on Reduction of Interval Cancer Rates in Women with Dense Breasts.*

\begin{tabular}{|c|c|c|c|c|c|}
\hline Screening modality & $\begin{array}{c}\text { Number of } \\
\text { women reported }\end{array}$ & $\begin{array}{l}\text { Incremental CDR } \\
\text { per } 1000 \text { women } \\
\text { screened }\end{array}$ & $\begin{array}{l}\text { Incremental invasive } \\
\text { CDR per } 1000 \text { women } \\
\text { screened }\end{array}$ & $\begin{array}{l}\text { Incremental recall } \\
\text { rate per } 100 \text { women } \\
\text { screened }\end{array}$ & $\begin{array}{l}\text { Reduced } \\
\text { interval cancers }\end{array}$ \\
\hline$M R I^{62,64,65}$ & 9256 & 16.0 & 12.1 & 10.4 & Yes \\
\hline$M R I$ after $\mathrm{DBT}^{63}$ & 1444 & 9.7 & 6.9 & 21.5 & Not yet evaluated \\
\hline CEM $^{66,67}$ & $13 \mid 1$ & 10.7 & 8.4 & 15 & Not yet evaluated \\
\hline Ultrasound ${ }^{61,62,75}$ & 452,743 & $2.0-2.7$ & $1.8-2.3$ & $7.6-10.6$ & Yes \\
\hline
\end{tabular}

Abbreviations: CDR, cancer detection rate; DBT, digital breast tomosynthesis; CEM, contrast-enhanced mammography.

* Reproduced with permission from. ${ }^{75}$

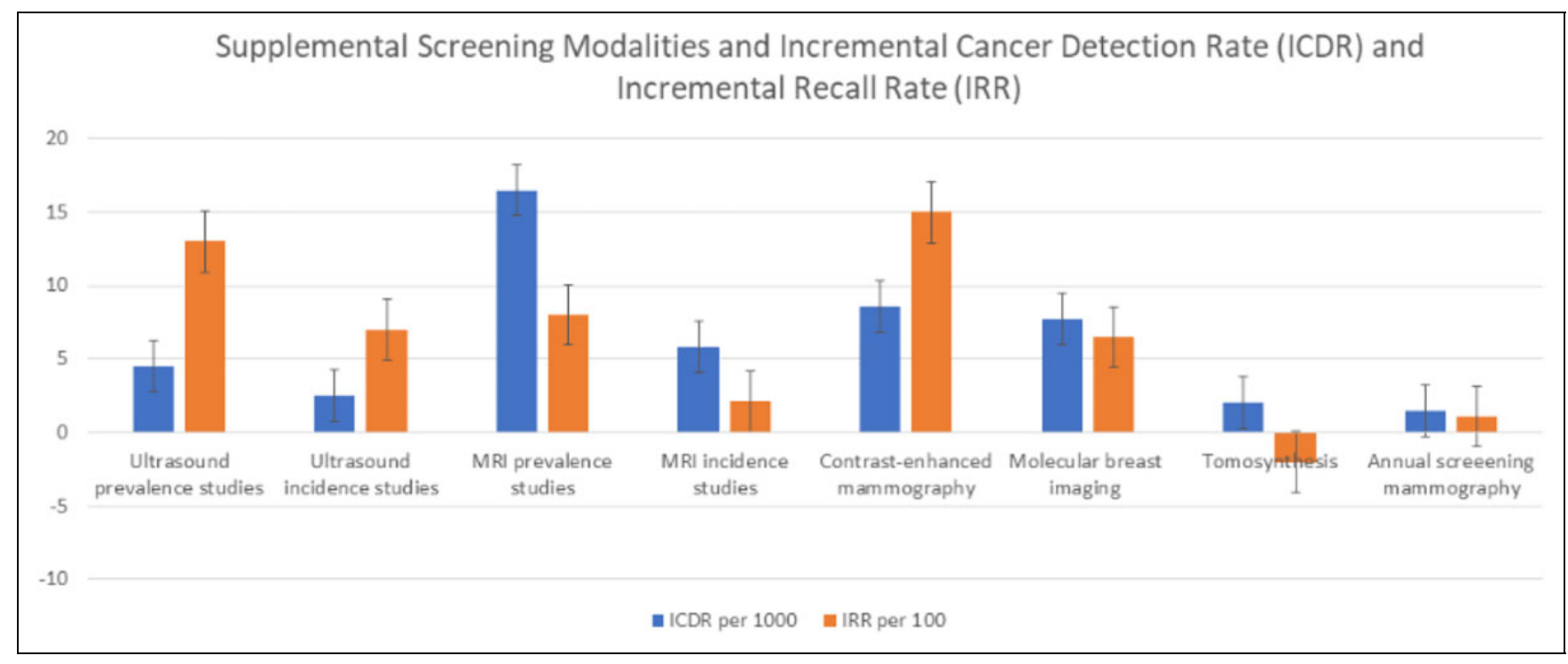

Figure 3. Bar graph demonstrating the different incremental cancer detection and recall rates for various supplemental screening modalities.

of all breast densities, interval cancers accounted for $0.05 \%$ of cancers detected with ultrasound as compared with $0.10 \%$ of cancers in the control group. ${ }^{72}$ In a retrospective prevalence study, Corsetti et al found that supplemental breast ultrasound had an ICR in women with dense breasts of 1.1 per 1000 screened women, which was similar to the ICR for women with non-dense breasts. ${ }^{73}$ In the ACRIN 6666 trial, Berg et al showed ICR of 1.2 per 1000 after combined mammography and supplemental US screening in women with dense breasts. ${ }^{62}$ In the DENSE trial, a prospective Dutch randomized trial of women with extremely dense breasts, the ICR in women who received supplemental breast MRI was 0.8 per 1000 as compared with 5 per 1000 in those who did not. ${ }^{65}$ The ability to maintain reduced ICRs in multiple rounds of screening with MRI is still unknown. ${ }^{35}$ The most recent screening tomosynthesis study of a 5-year period found an ICR of 1.6 per 1000 screened women, compared with 2.8 per 1000 screened women in the control group. ${ }^{74}$ Recalls are highest in prevalence scans for any modality, and with supplemental US, recalls reported at $15.1 \%$, decreased to $7.4 \%$ in subsequent scans. ${ }^{62}$ Similarly with supplemental MRI screening, there were higher recalls of $9.5 \%$ in the DENSE trial in the prevalence scans which decreased to $3.2 \%$ on incidence screening. ${ }^{65}$

\section{Limitations}

Screening interval policy and even radiologists' recommendations did not necessarily translate into patient behavior and so not all women eligible for an annual mammogram would have received it. Unfortunately, we do not have access to data on compliance, so this might underestimate the value of performing annual screening in women with dense breasts. Furthermore, the recommendations for offering more frequent screening for women with dense breast tissue varied, with 3 jurisdictions offering annual screening by program policy and 1 offering biennial screening that could be modified based on radiologist recommendations. Another limitation is that reasons for the radiologists' recommendation of annual screening were not captured and could have included abnormal findings. Most Canadian screening programs defined "dense" breast tissue as $\geq 75 \%$ density (i.e. extremely dense), according to the BI-RADS 4th edition, while NB defined it as $\geq 50 \%$ (which 


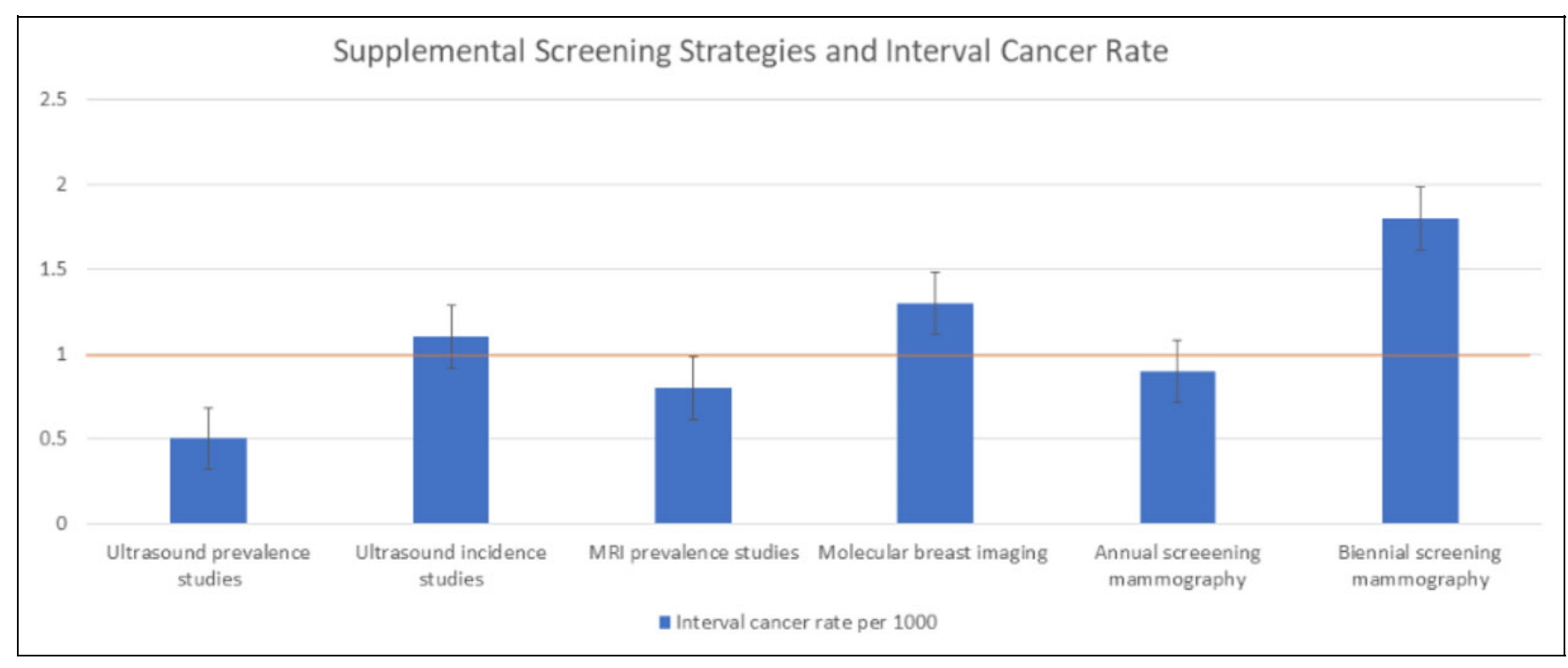

Figure 4. Bar graph demonstrating the different interval cancer rates for various supplemental screening modalities. * The red line indicates the threshold of interval cancer rate for an effective screening program that should not exceed I per 1000/women screened/year, for a sensitivity of $>75 \%$ within a population with a cancer incidence of $4 / 1000$.

would include heterogeneously dense breasts). If provinces and territories had recalled all women with dense breasts (i.e. categories $\mathrm{C}$ and $\mathrm{D}$ ) annually, the ICR would likely have been even lower. The current definition of dense breasts, according to the BI-RADS 5th edition, which includes both heterogeneously dense and extremely dense categories, avoids density percentages and is based on a subjective visual assessment. None of the screening programs used quantitative methods of determining breast tissue density. This study primarily pertains to patients with the densest breast tissue, BI-RADS category D, extremely dense, which applies to only about $7 \%$ of all screened women. In addition, the study was not able to explore whether the increased ICR translated into worse outcomes for women with dense breasts as stage of cancers and survival could not be assessed. However, previous studies have shown a survival benefit of 1-year over 2-year screening intervals. ${ }^{77} \mathrm{It}$ was not possible to assess for potential lower specificity and increased recalls that may occur with annual screening mammography with this study. Chiarelli et al found that specificity decreased with annual screening with increasing breast tissue density. ${ }^{78}$ Annual mammographic screening was not compared with other screening regimens using supplemental screening modalities, which is of increasing relevance in other countries where there is far greater uptake of supplemental ultrasound screening for women with dense breasts, such as the USA, France, Austria, and a few other European countries. ${ }^{27,75,79}$

Currently, in Canada, access to supplemental screening with additional modalities varies according to jurisdiction. MRI supplemental screening for women with dense breasts is recommended in several countries but currently there is limited access to breast MRI in Canada to promote this as a population-based strategy. The European Commission Initiative for Breast Cancer Screening and Diagnosis guidelines suggest not implementing tailored screening (with ultrasonography or MRI) in women with dense breast tissue.$^{80}$ Nickel et al have raised concerns about breast tissue density notification and concluded that evidence on whether benefit outweighs harm is required to inform future screening practice ${ }^{81}$ Consensus on the balance of benefits versus harms has not yet been established. Although evidence is rapidly emerging, more studies are underway to evaluate sustainability and cost effectiveness. Lastly, the study evaluated women that were screened in 2008-2010 to permit assessment of subsequent cancers diagnosed; however, this study does not reflect improvements in technology such as more widespread use of digital mammography and even tomosynthesis. It is noted that although tomosynthesis increases CDR in all breast densities, the greatest increases are in categories B and $\mathrm{C}$, with very few additional cancers found in category $\mathrm{D}^{76,82,83}$ There is considerable uncertainty about the cost effectiveness of annual mammography. ${ }^{84}$ Research on the effectiveness of screening strategies has been suggested.

This study is the first to demonstrate a reduced ICR with annual screening policies for women with dense breast tissue participating in a population-based screening program. Women with dense breast tissue (particularly those with densest breasts) may benefit from annual screening, as evidenced by a lower ICR compared to biennial screening. Potential further benefits and harms of supplemental screening modalities need to be considered in the context of ICRs and screening interval. Ultimately, all women deserve an equal opportunity for early cancer detection regardless of breast density.

\section{Acknowledgments}

Acknowledgment to Greg Doyle (NL), Kelly Bunzeluk (MB), Shirley Koch (New Brunswick), Bin Zhang MD (New Brunswick), and Isabelle Theberge (QC) for their valuable insights and contributions to the data and manuscript. 


\section{Declaration of Conflicting Interests}

The author(s) declared no potential conflicts of interest with respect to the research, authorship, and/or publication of this article.

\section{Funding}

The author(s) received no financial support for the research, authorship, and/or publication of this article.

\section{ORCID iDs}

Dianne Zakaria (D) https://orcid.org/0000-0001-8610-1248

Wendie Berg, MD, PhD (D) https://orcid.org/0000-0002-8792-6185

\section{References}

1. Hellquist BN, Duffy SW, Abdsaleh S, et al. Effectiveness of population-based service screening with mammography for women ages 40 to 49 years: evaluation of the Swedish Mammography Screening in Young Women (SCRY) cohort. Cancer. 2011;117(4):714-722.

2. Smith RA, Duffy SW, Gabe R, Tabar L, Yen AM, Chen TH. The randomized trials of breast cancer screening: what have we learned? Radiol Clin North Am. 2004;42(5):793-806, v.

3. Boyd NF, Guo H, Martin LJ, et al. Mammographic density and the risk and detection of breast cancer. $N$ Engl J Med. 2007;356(3): 227-236.

4. Engmann NJ, Golmakani MK, Miglioretti DL, Sprague BL, Kerlikowske K, Breast Cancer Surveillance C. Populationattributable risk proportion of clinical risk factors for breast cancer. JAMA Oncol. 2017;3(9):1228-1236.

5. Boyd NF, Dite GS, Stone J, et al. Heritability of mammographic density, a risk factor for breast cancer. $N$ Engl J Med. 2002; 347(12):886-894.

6. McCormack VA, dos Santos Silva I. Breast density and parenchymal patterns as markers of breast cancer risk: a meta-analysis. Cancer Epidemiol Biomarkers Prev. 2006;15(6):1159-1169.

7. van der Waal D, Verbeek ALM, Broeders MJM. Breast density and breast cancer-specific survival by detection mode. BMC Cancer. 2018;18(1):386.

8. Chiu SY, Duffy S, Yen AM, Tabar L, Smith RA, Chen HH. Effect of baseline breast density on breast cancer incidence, stage, mortality, and screening parameters: 25-year follow-up of a Swedish mammographic screening. Cancer Epidemiol Biomarkers Prev. 2010;19(5):1219-1228.

9. Eriksson L, Czene K, Rosenberg LU, Tornberg S, Humphreys K, Hall P. Mammographic density and survival in interval breast cancers. Breast Cancer Res. 2013;15(3):R48.

10. van der Waal D, Ripping TM, Verbeek AL, Broeders MJ. Breast cancer screening effect across breast density strata: a case-control study. Int J Cancer. 2017;140(1):41-49.

11. Kerlikowske K, Sprague BL, Tosteson ANA, et al. Strategies to identify women at high risk of advanced breast cancer during routine screening for discussion of supplemental imaging. JAMA Intern Med. 2019;179(9):1230-1339.

12. Kerlikowske K, Cook AJ, Buist DS, et al. Breast cancer risk by breast density, menopause, and postmenopausal hormone therapy use. J Clin Oncol. 2010;28(24):3830-3837.
13. Shawky MS, Martin H, Hugo HJ, et al. Mammographic density: a potential monitoring biomarker for adjuvant and preventative breast cancer endocrine therapies. Oncotarget. 2017;8(3): 5578-5591.

14. Atkinson C, Warren R, Bingham SA, Day NE. Mammographic patterns as a predictive biomarker of breast cancer risk: effect of tamoxifen. Cancer Epidemiol Biomarkers Prev. 1999;8(10): 863-866.

15. Pinker K. Beyond breast density: radiomic phenotypes enhance assessment of breast cancer risk. Radiology. 2019;290(1):50-51.

16. FDA-NIH Biomarker Working Group. BEST (Biomarkers, EndpointS, and other Tools) Resource [Internet]. Silver Spring (MD): Food and Drug Administration (US); 2016-. FDA-NIH Biomarker Working Group. 2016 Jan 28 [Updated 2021 Jan 25] Accessed 2021. https://www.ncbi.nlm.nih.gov/books/NBK338449/ Copublished by National Institutes of Health (US), Bethesda (MD).

17. Skarping I, Fornvik D, Sartor H, Heide-Jorgensen U, Zackrisson $\mathrm{S}$, Borgquist S. Mammographic density is a potential predictive marker of pathological response after neoadjuvant chemotherapy in breast cancer. BMC Cancer. 2019;19(1):1272.

18. Woodard GA, Ray KM, Joe BN, Price ER. Qualitative radiogenomics: association between oncotype DX test recurrence score and BI-RADS mammographic and breast MR imaging features. Radiology. 2018;28(1):60-70.

19. Huang YS, Chen JL, Huang CS, et al. High mammographic breast density predicts locoregional recurrence after modified radical mastectomy for invasive breast cancer: a case-control study. Breast Cancer Res. 2016;18(1):120.

20. Eriksson L, Czene K, Rosenberg L, Humphreys K, Hall P. Possible influence of mammographic density on local and locoregional recurrence of breast cancer. Breast Cancer Res. 2013; 15(4):R56.

21. D'Orsi C, Sickles E, Mendelson E, Morris E. ACR BI-RADS ${ }^{\circledR}$ Atlas, Breast Imaging Reporting and Data System. American College of Radiology; 2013.

22. Radiology ACo. ACR BI-RADS Atlas-Mammography, 4th ed. In: Reston VA, ed. American College of Radiology; 2003.

23. Pesce K, Tajerian M, Chico MJ, et al. Interobserver and intraobserver variability in determining breast density according to the fifth edition of the BI-RADS(R) Atlas. Radiologia. 2020;62(6): 481-486.

24. Sprague BL, Conant EF, Onega T, et al. Variation in mammographic breast density assessments among radiologists in clinical practice: a multicenter observational study. Ann Intern Med. 2016;165(7):457-464.

25. Sprague BL, Gangnon RE, Burt V, et al. Prevalence of mammographically dense breasts in the United States. J Natl Cancer Inst. 2014;106(10):dju255.

26. Cappello NM, Richetelli D, Lee CI. The impact of breast density reporting laws on women's awareness of density-associated risks and conversations regarding supplemental screening with providers. J Am Coll Radiol. 2019;16(2):139-146.

27. Densebreast-info.org. Accessed June 17, 2021. Published 2021. https://densebreast-info.org/wp-content/uploads/2021/02/Table. Europe.Guidelines.2Feb2021.pdf 
28. Canada DB. Published 2021. Accessed 2021. https://densebreasts canada.ca/faq/

29. Canadian Partnership Against Cancer. Breast Cancer Screening in Canada: Monitoring and Evaluation of Quality IndicatorsResults Report, January 2011 to December 2012. Canadian Partnership Against Cancer; 2017:1-64.

30. Kerlikowske $\mathrm{K}$, Zhu W, Tosteson AN, et al. Identifying women with dense breasts at high risk for interval cancer: a cohort study. Ann Intern Med. 2015; 162(10):673-681.

31. Mordang JJ, Gubern-Merida A, Bria A, et al. The importance of early detection of calcifications associated with breast cancer in screening. Breast Cancer Res Treat. 2018;167(2):451-458.

32. Holm J, Humphreys K, Li J, et al. Risk factors and tumor characteristics of interval cancers by mammographic density. J Clin Oncol. 2015;33(9):1030-1037.

33. Domingo L, Salas D, Zubizarreta R, et al. Tumor phenotype and breast density in distinct categories of interval cancer: results of population-based mammography screening in Spain. Breast Cancer Res. 2014;16(1):R3.

34. Strand F, Azavedo E, Hellgren R, et al. Localized mammographic density is associated with interval cancer and large breast cancer: a nested case-control study. Breast Cancer Res. 2019;21(1):8.

35. Ciatto S, Visioli C, Paci E, Zappa M. Breast density as a determinant of interval cancer at mammographic screening. Br J Cancer. 2004;90(2):393-396.

36. McCarthy AM, Barlow WE, Conant EF, et al. Breast cancer with a poor prognosis diagnosed after screening mammography with negative results. JAMA Oncol. 2018;4(7):998-1001.

37. Houssami N, Hunter K. The epidemiology, radiology and biological characteristics of interval breast cancers in population mammography screening. NPJ Breast Cancer. 2017;3(1):1-3.

38. Porter PL, El-Bastawissi AY, Mandelson MT, et al. Breast tumor characteristics as predictors of mammographic detection: comparison of interval- and screen-detected cancers. J Natl Cancer Inst. 1999;91(23):2020-2028.

39. Gilliland FD, Joste N, Stauber PM, et al. Biologic characteristics of interval and screen-detected breast cancers. J Natl Cancer Inst. 2000;92(9):743-749.

40. Kirsh VA, Chiarelli AM, Edwards SA, et al. Tumor characteristics associated with mammographic detection of breast cancer in the Ontario breast screening program. J Natl Cancer Inst. 2011; 103(12):942-950.

41. Niraula S, Biswanger N, Hu P, Lambert P, Decker K. Incidence, characteristics, and outcomes of interval breast cancers compared with screening-detected breast cancers. JAMA Netw Open. 2020; 3(9):e2018179.

42. Cancer IAfRo. IARC: Breast Cancer Screening. International Agency for Research on Cancer; 2016:470.

43. Cancer CPA. CPAC: Breast Cancer Screening in Canada: Monitoring and Evaluation of Quality Indicators-Results Report, January 2011 to December 2012. Canadian Partnership Against Cancer; 2017.

44. van Gils CH, Otten JD, Hendriks JH, Holland R, Straatman H, Verbeek AL. High mammographic breast density and its implications for the early detection of breast cancer. J Med Screen. 1999; 6(4):200-204.
45. Coldman AJ, Phillips N. Breast cancer survival and prognosis by screening history. Br J Cancer. 2014;110(3):556-559.

46. Cancer CPA. Report From the Evaluation Indicators Working Group: Guidelines for Monitoring Breast Cancer Screening Program Performance. Canadian Partnership Against Cancer; February, 2013.

47. Canadian Partnership Against Cancer. Breast Cancer Screening in Canada: Monitoring and Evaluation of Quality IndicatorsResults Report, January 2009-December 2010. Canadian Partnership Against Cancer; 2015:1-26.

48. O’Brien KM, Dwane F, Kelleher T, Sharp L, Comber H. Interval cancer rates in the Irish National Breast Screening Programme. $J$ Med Screen. 2015;22(3):136-143.

49. Hofvind S, Holen A, Roman M, Sebuodegard S, Puig-Vives M, Akslen L. Mode of detection: an independent prognostic factor for women with breast cancer. J Med Screen. 2016; 23(2):89-97.

50. Bordas P, Jonsson H, Nystrom L, Lenner P. Survival from invasive breast cancer among interval cases in the mammography screening programmes of northern Sweden. Breast (Edinburgh, Scotland). 2007;16(1):47-54.

51. Vitak B, Olsen KE, Manson JC, Arnesson LG, Stal O. Tumour characteristics and survival in patients with invasive interval breast cancer classified according to mammographic findings at the latest screening: a comparison of true interval and missed interval cancers. Eur Radiol. 1999;9(3):460-469.

52. Zackrisson S, Janzon L, Manjer J, Andersson I.Improved survival rate for women with interval breast cancer-results from the breast cancer screening programme in Malmo, Sweden 19761999. J Med Screen. 2007;14(3):138-143.

53. Fracheboud J, de Koning HJ, Beemsterboer PM, et al. Interval cancers in the Dutch breast cancer screening programme. $\mathrm{Br} J$ Cancer. 1999;81(5):912-917.

54. Defossez G, Quillet A, Ingrand P. Aggressive primary treatments with favourable 5-year survival for screen-interval breast cancers. BMC Cancer. 2018;18(1):393.

55. Hofvind S, Sagstad S, Sebuodegard S, Chen Y, Roman M, Lee CI. Interval breast cancer rates and histopathologic tumor characteristics after false-positive findings at mammography in a population-based screening program. Radiology. 2018;287(1):58-67.

56. Lehman CD, Arao RF, Sprague BL, et al. National performance benchmarks for modern screening digital mammography: update from the breast cancer surveillance consortium. Radiology. 2017; 283(1):49-58.

57. Ciatto S, Houssami N, Bernardi D, et al. Integration of 3D digital mammography with tomosynthesis for population breast-cancer screening (STORM): a prospective comparison study. Lancet Oncol. 2013;14(7):583-589.

58. Rafferty EA, Park JM, Philpotts LE, et al. Assessing radiologist performance using combined digital mammography and breast tomosynthesis compared with digital mammography alone: results of a multicenter, multireader trial. Radiology. 2013;266(1):104-113.

59. Conant EF, Barlow WE, Herschorn SD, et al. Association of digital breast tomosynthesis vs digital mammography with cancer detection and recall rates by age and breast density. JAMA Oncol. 2019;5(5):635-642. 
60. Osteras BH, Martinsen ACT, Gullien R, Skaane P. Digital mammography versus breast tomosynthesis: impact of breast density on diagnostic performance in population-based screening. Radiology. 2019;293(1):60-68.

61. Yang L, Wang S, Zhang L, et al. Performance of ultrasonography screening for breast cancer: a systematic review and meta-analysis. BMC Cancer. 2020;20(1):499.

62. Berg WA, Zhang Z, Lehrer D, et al. Detection of breast cancer with addition of annual screening ultrasound or a single screening MRI to mammography in women with elevated breast cancer risk. JAMA. 2012;307(13):1394-1404.

63. Comstock CE, Gatsonis C, Newstead GM, et al. Comparison of abbreviated breast MRI vs digital breast tomosynthesis for breast cancer detection among women with dense breasts undergoing screening. JAMA. 2020;323(8):746-756.

64. Kuhl CK, Strobel K, Bieling H, Leutner C, Schild HH, Schrading S. Supplemental breast MR imaging screening of women with average risk of breast cancer. Radiology. 2017;283(2):361-370.

65. Bakker MF, de Lange SV, Pijnappel RM, et al. Supplemental MRI screening for women with extremely dense breast tissue. $N$ Engl J Med. 2019;381(22):2091-2102.

66. Sorin V, Yagil Y, Yosepovich A, et al. Contrast-enhanced spectral mammography in women with intermediate breast cancer risk and dense breasts. AJR Am J Roentgenol. 2018;211(5):W267-W274.

67. Sung JS, Lebron L, Keating D, et al. Performance of dual-energy contrast-enhanced digital mammography for screening women at increased risk of breast cancer. Radiology. 2019;293(1):81-88.

68. Shermis RB, Wilson KD, Doyle MT, et al. Supplemental breast cancer screening with molecular breast imaging for women with dense breast tissue. AJR Am J Roentgenol. 2016;207(2):450-457.

69. Rhodes DJ, Hruska CB, Conners AL, et al. Journal club: molecular breast imaging at reduced radiation dose for supplemental screening in mammographically dense breasts. AJR Am J Roentgenol. 2015;204(2):241-251.

70. Rhodes DJ, Hruska CB, Phillips SW, Whaley DH, O'Connor MK. Dedicated dual-head gamma imaging for breast cancer screening in women with mammographically dense breasts. Radiology. 2011;258(1):106-118.

71. Veenhuizen SGA, de Lange SV, Bakker MF, et al. Supplemental breast MRI for women with extremely dense breasts: results of the second screening round of the DENSE trial. Radiology. 2021; 299(2):278-286.

72. Ohuchi N, Suzuki A, Sobue T, et al. Sensitivity and specificity of mammography and adjunctive ultrasonography to screen for breast cancer in the Japan strategic anti-cancer randomized trial (J-START): a randomised controlled trial. Lancet. 2016; 387(10061):341-348.
73. Corsetti V, Houssami N, Ghirardi M, et al. Evidence of the effect of adjunct ultrasound screening in women with mammographynegative dense breasts: interval breast cancers at 1 year follow-up. Eur J Cancer. 2011;47(7):1021-1026.

74. Johnson K, Lang K, Ikeda DM, Akesson A, Andersson I, Zackrisson $\mathrm{S}$. Interval breast cancer rates and tumor characteristics in the prospective population-based Malmo breast tomosynthesis screening trial. Radiology. 2021;299(3):559-567.

75. Berg WA, Rafferty EA, Friedewald SM, Hruska CB, Rahbar H.Screening algorithms in dense breasts: AJR expert panel narrative review. AJR Am J Roentgenol. 2021;216(2): 275-294.

76. Rafferty EA, Durand MA, Conant EF, et al. Breast cancer screening using tomosynthesis and digital mammography in dense and nondense breasts. JAMA. 2016;315(16):1784-1786.

77. Wai ES, D'Yachkova Y, Olivotto IA, et al. Comparison of 1- and 2-year screening intervals for women undergoing screening mammography. Br J Cancer. 2005;92(5):961-966.

78. Chiarelli AM, Blackmore KM, Mirea L, et al. Annual vs biennial screening: diagnostic accuracy among concurrent cohorts within the Ontario Breast Screening Program. J Natl Cancer Inst. 2020; 112(4):400-409.

79. (GRED) Gdrslédd. Éthique et dépistage organisé du cancer du sein en France-Rapport du Groupe de réflexion sur l'éthique du dépistage. In: CÉdld connaissances, ed. Boulogne-Billancourt. Ouvrage édité par l'INCa; 2012:84.

80. Schunemann HJ, Lerda D, Quinn C, et al. Breast cancer screening and diagnosis: a synopsis of the European breast guidelines. Ann Intern Med. 2020;172(1):46-56.

81. Nickel B, Farber R, Brennan M, Hersch J, McCaffery K, Houssami N. Breast density notification: evidence on whether benefit outweighs harm is required to inform future screening practice. BMJ Evid Based Med. 2020.

82. Tagliafico AS, Mariscotti G, Valdora F, et al. A prospective comparative trial of adjunct screening with tomosynthesis or ultrasound in women with mammography-negative dense breasts (ASTOUND-2). Eur J Cancer. 2018;104:39-46.

83. Tagliafico AS, Calabrese M, Mariscotti G, et al. Adjunct screening with tomosynthesis or ultrasound in women with mammography-negative dense breasts: interim report of a prospective comparative trial. J Clin Oncol. 2016;34(16): 1882-1888.

84. Pataky R, Ismail Z, Coldman AJ, et al. Cost-effectiveness of annual versus biennial screening mammography for women with high mammographic breast density. J Med Screen. 2014;21(4): 180-188. 